\title{
Electrochemical Corrosion Control for Reinforced Concrete Structures-A Review
}

\author{
Bingbing Guo ${ }^{l, *}$, Guofu Qiao ${ }^{2}$, Ditao Niu ${ }^{1}$, Jinping $O u^{2}$ \\ ${ }^{1}$ School of Civil Engineering / Key Lab of Engineering Structural Safety and Durability / National \\ Key Laboratory of Green Building in West China, Xi'an University of Architecture and Technology, \\ Xi'an, 710055, China \\ ${ }^{2}$ School of Civil Engineering / Key Lab of Smart Prevention and Mitigation of Civil Engineering \\ Disasters of the Ministry of Industry Information Technology / Key Lab of Structures Dynamic \\ Behavior and Control of the Ministry of Education, Harbin Institute of Technology, Harbin 150090, \\ China \\ *E-mail: guobingbing212@163.com
}

doi: $10.20964 / 2020.06 .24$

Received: 8 January 2020 / Accepted: 16 March 2020 / Published: 10 May 2020

Electrochemical corrosion control (ECC), including cathodic protection (CP), electrochemical chlorine removal (ECR) and electrochemical realkalisation (ER), is extremely effective for improving the durability of reinforced concrete structures. This paper summarizes recent studies on ECC. The findings indicate that long-term ECC with an intermittent small current can achieve CP, ECR, and ER, making it an attractive approach. It is imperative to develop a numerical model of ECC that includes ionic transport in pore solution, oxygen and water transports, thermodynamic reactions, and electrode kinetics. Additionally, an intelligent system integrating corrosion monitoring and intermittent ECC will be beneficial.

Keywords: reinforced concrete structures; corrosion control; cathodic protection (CP); electrochemical chloride removal (ECR); electrochemical realkalisation (ER)

\section{$\underline{\text { FULL TEXT }}$}

(C) 2020 The Authors. Published by ESG (www.electrochemsci.org). This article is an open access article distributed under the terms and conditions of the Creative Commons Attribution license (http://creativecommons.org/licenses/by/4.0/). 